einstein

Official Publication of the Instituto Israelita de Ensino e Pesquisa Albert Einstein

ISSN: 1679-4508 | e-ISSN: 2317-6385
How to cite this article:

Khawaja UA, Franchi T, Pedersini P, TovaniPalone MR. Declining rates of global routine vaccination coverage amidst the COVID-19 syndemic: a serious public health concern. einstein (São Paulo). 2021;19:eED6552.

Corresponding author:

Marcos Roberto Tovani-Palone

Avenida Bandeirantes, 3.900 - Vila Monte Alegre Zip code: 14049-900 - Ribeirão Preto, SP, Brazil Phone: (55 16) 3315-3001

E-mail:marcos_palone@hotmail.com

\section{Copyright 2021}

\section{(c) By}

This content is licensed

under a Creative Commons

Attribution 4.0 International License.
EDITORIAL

\section{Declining rates of global routine} vaccination coverage amidst the COVID-19 syndemic:

\section{a serious public health concern}

\author{
Taxas decrescentes de cobertura global da vacinação \\ de rotina em meio à sindemia da COVID-19: \\ um grave problema de saúde pública
}

\author{
Uzzam Ahmed Khawaja'1, Thomas Franchi², Paolo Pedersini³, Marcos Roberto Tovani-Palone ${ }^{4}$ \\ Jinnah Medical \& Dental College, Karachi, Sindh, Pakistan. \\ 2 University of Sheffield, Sheffield, United Kingdom. \\ ${ }^{3}$ IRCCS Fondazione Don Carlo Gnocchi, Milan, Italy. \\ ${ }^{4}$ Faculdade de Medicina de Ribeirão Preto, Universidade de São Paulo, Ribeirão Preto, SP, Brazil.
}

DOI: 10.31744/einstein_journal/2021ED6552

At the end of 2019, a novel coronavirus named severe acute respiratory syndrome coronavirus 2 (SARS-CoV-2), began to spread in the city of Wuhan, China, causing an outbreak of a highly transmissible and potentially severe viral pneumonia. This novel coronavirus disease, known as coronavirus disease 2019 (COVID-19), rapidly advanced all over the globe and was considered a pandemic in March 2020. ${ }^{(1,2)}$ However, in a recent article, COVID-19 has been redefined as a syndemic, since a background of social and economic disparity increased the adverse effects of the SARS-CoV-2 infection, together with several non-communicable diseases. ${ }^{(3)}$ In an effort to reduce the increasing morbidity and mortality rates of COVID-19 across the world, societies are trying to limit the routine utilization of healthcare facilities, to reduce the associated deleterious impacts. ${ }^{(4,5)}$

The disease has halted many usual activities, such as commerce, travel and healthcare services. Amid global lockdowns, daily healthcare services and elective surgical procedures have been cancelled across multiple healthcare settings. Furthermore, healthcare workers have been retrained and redeployed to prioritize the provision of care to clinically deteriorating COVID-19 patients. Simultaneously, the syndemic has interrupted routine immunization practices across all age groups, particularly for the pediatric population. Delays, reorganization or suspension of these routine vaccinations may lead to a surge in numbers of infections and subsequent deaths due to vaccine-preventable diseases. Part of the population may also become susceptible to diseases that were previously controlled or eradicated. ${ }^{(6)}$ Prevention and control measures to avoid spread of COVID-19 have hindered child and mass immunization efforts globally, placing millions of children at risk of other potentially fatal vaccinepreventable diseases. ${ }^{(7)}$ The most affected vaccination campaigns include those for measles, poliomyelitis, diphtheria, pertussis, tetanus and meningitis. Therefore, some vaccine-preventable diseases are now making a comeback, thereby putting local populations at risk. ${ }^{(8)}$ 
Some factors, such as parental fear, lockdown measures, prioritizing COVID-19 patients, and logistics delivery issues (such as vaccine transport delays), have greatly contributed to delayed and interrupted immunizations. According to the World Health Organization (WHO), the United Nations International Children's Emergency Fund (Unicef), the Global Vaccine Alliance (GAVI), and the Sabin Vaccine Institute, routine immunization programs have been significantly affected in at least 68 countries, affecting approximately 80 million children. In GAVI-supported low-income countries, an additional 24 million individuals are at risk of missing out on vaccines against measles, poliomyelitis, rotavirus, meningitis, rubella and human papillomavirus. ${ }^{(9)}$

In the first five months of the syndemic, numerous countries had suspended their routine immunization campaigns. ${ }^{(9)}$ Cessation of vaccination campaigns has led to alarming and potentially devastating public health outcomes, with diphtheria recently reemerging in some countries, such as Venezuela, Pakistan, Nepal, Bangladesh and Yemen, where population displacement greatly effects public health systems. Similarly, resurgence of cholera has been reported in Bangladesh, Cameroon, Mozambique, South Sudan and Yemen. ${ }^{(10)}$ Through April 1st to 15, 2020, a complete suspension of routine immunizations was observed in Vietnam, while India's routine immunization program was also disrupted, for health workers were redeployed in an effort to curb the spread of the syndemic. ${ }^{(6)}$

As per the Global Polio Eradication Initiative (GPEI), it was recommended suspend the vaccination campaigns against poliomyelitis until the second half of 2020. (11) Pakistan also postponed their polio catch-up immunization campaigns until June $1{ }^{\text {st }}, 2020 .{ }^{(6)}$ The syndemic caused the suspension of 46 poliovirus immunization campaigns in 38 countries, most notably in African nations. Recently, over 30 countries reported a mutated vaccine-derived strain of poliovirus, ${ }^{\left({ }^{9}\right)}$ and Niger reported a recent polio outbreak. ${ }^{(12)}$ Pakistan and Afghanistan have further reported a wild poliovirus type 1 , while cases of type 2 poliovirus, mutated from the oral vaccine, have appeared in Chad, Ethiopia, Ghana and Pakistan. ${ }^{(13)}$

Furthermore, it is important to consider in the current context that measles, a disease that causes severe morbidity and has a case fatality rate of $0.2 \%$, is far more contagious (basic reproduction rate $-\mathrm{R}_{0}$ - of 12-16) than COVID-19.(14) Measles weakens the immune system for a long period of time, resulting in immune amnesia, which leaves patients susceptible to other infections. ${ }^{(15)}$ In England, during the first three weeks of national lockdown, the numbers of measles, mumps, and rubella vaccines delivered dropped by $20 \%$, with smaller uptake drops were reported amongst children in Scotland. ${ }^{(16)}$ Similarly, immunization coverage has simultaneously decreased in the adult population too, due to similar concerns previously described, and the fear of attending healthcare facilities. ${ }^{(17)}$ Pneumococcal and influenza vaccines are also being affected in light of COVID-19. A rise of COVID-19 incidence, alongside mortality, has been noticed in patients with chronic lung and cardiovascular diseases as well as diabetes, all of which are recognized risk factors for pneumococcal infections. ${ }^{(18)}$ However, there is limited data available regarding influenza's interaction with COVID-19. (6,19,20) $^{-1}$ In the United States, the coverage of publicly funded vaccines, including hepatitis, meningitis, poliomyelitis and rotavirus, declined drastically in comparison to 2019. In New York City, vaccinations have dropped by an overall average of $63 \%$, rising to $91 \%$ for children above 2 years of age, whilst in the state of California, rates have declined by $40 \% .^{(21)}$ Furthermore, the state of Ohio reported a $45 \%$ decline in vaccination rates in its pediatric population. Whilst under normal circumstances, 1,000 measles shots would be given monthly, in April 2020, only 32 were reported in the state. ${ }^{(22)}$

Hesitancy and refusal to accept vaccination have been a serious public health concern for a number of years, both before and during the COVID-19 syndemic. Many barriers to vaccination, most of them centering on concerns about vaccine safety, are well described in the literature. ${ }^{(23)}$ However, the reasons for vaccination delay or refusal change over time, as highlighted by this syndemic. Fear mongering should be fought with verified information, as sharing false and nonauthenticated news and opinions with vulnerable communities has significantly contributed to skepticism surrounding the development and uptake of vaccines. ${ }^{(24)}$ Immunization is amongst the most effective public health measures to prevent the spread of diseases. To raise awareness and fight misinformation, high-level activity is required to preserve ongoing vaccination coverage and limit preventable infections. There is an urgent need to encourage government action, increase support to communities and reassure the public about the importance and safety of attending primary care units for routine vaccination during the COVID-19 syndemic. An effective vaccine is likely to be the most crucial method to control and curb the syndemic, as agreed upon by public health officials globally. A minimum of one to two years is typically needed to develop an effective vaccine, ${ }^{(25-28)}$ and an efficacious 
vaccine is deemed vital to prevent morbidity and mortality. ${ }^{(29)}$ To date, dozens of candidate SARS-CoV-2 vaccines have or are undergoing clinical trials, ${ }^{(30)}$ with a number already approved and being implemented for mass public vaccination. ${ }^{(31,32)}$ However, Russia and China have been reported to perform SARS-CoV-2 vaccination outside of clinical trials, which has encountered widespread criticism, in light of uncertain safety profiles of these candidate vaccines, without robust safety and efficacy data being made widely available from phase 3 clinical trials. ${ }^{(33,34)}$

According to the WHO, a "clear demonstration of efficacy (on population basis) ideally with $\sim 50 \%$ point estimate", is the minimum standard for a newly developed vaccine to be accepted for mass use against COVID-19. The efficacy of such a vaccine should be checked against "disease, severe disease, and/or shedding/transmission" endpoints. ${ }^{(35)}$ Data for longterm efficacy and safety profiles are also needed. To support the latter, clinical trials of sufficient duration and participant numbers are required to further assess whether the vaccines make COVID-19 more hazardous (the so-called disease enhancement). ${ }^{(36,37)}$ Evidence is needed to support the use of SARS-CoV-2 vaccines, and prevent the negative impacts on the public acceptance of them, which could hinder the control of COVID-19 spread, as well as deleteriously affect the administration of routine vaccines for other communicable diseases. ${ }^{(38)}$

In conclusion, public authorities are setting up fasttrack approval processes for effective vaccines against SARS-CoV-2, and strong vaccination campaigns are already underway in several countries. Vaccination hesitancy remains a persistent concern for both the SARS-CoV-2 vaccination and all other routine immunization programs. It is believed that effective public health measures can reduce the impact that vaccine delay or refusal has on routine immunization processes, thereby preventing the reemergence of previously eradicated diseases.

\section{AUTHORS' INFORMATION}

Khawaja UA: http://orcid.org/0000-0002-8442-5174

Franchi T: http://orcid.org/0000-0003-2565-8098

Pedersini P: http://orcid.org/0000-0003-0224-1783

Tovani-Palone MR: http://orcid.org/0000-0003-1149-2437

\section{REFERENCES}

1. Wu JT, Leung K, Leung GM. Nowcasting and forecasting the potential domestic and international spread of the 2019-nCoV outbreak originating in Wuhan, China: a modelling study. Lancet. 2020;395(10225):689-7. Erratum in: Lancet. 2020 Feb 4.
2. Hui DS, I Azhar E, Madani TA, Ntoumi F, Kock R, Dar O, et al. The continuing 2019-nCoV epidemic threat of novel coronaviruses to global health - The latest 2019 novel coronavirus outbreak in Wuhan, China. Int J Infect Dis. 2020;91:264-6.

3. Horton R. Offline: COVID-19 is not a pandemic. Lancet. 2020;396(10255):874.

4. Ferguson NM, Laydon D, Nedjati-Gilani G, Imai N, Ainslie K, Baguelin M, Bhatia S, Boonyasiri A, Cucunubá Z, Cuomo-Dannenburg G, Dighe A, Dorigatti I, Fu H, Gaythorpe K, Green W, Hamlet A, Hinsley W,Okell LC, van Elsland S, Thompson H, Verity R, Volz E, Wang H, Wang Y, Walker PG, Walters C, Peter Whittaker WC, Donnelly CA, Riley S, Ghani AC; On behalf of the Imperial College COVID-19 Response Team. Report 9- Impact of non-pharmaceutical interventions (NPIs) to reduce COVID-19 mortality and healthcare demand. London: Imperial College London; 2020 [cited 2021 Feb 3]. Available from: https://www.imperial.ac.uk/mrc-global-infectious-disease-analysis/ covid-19/report-9-impact-of-npis-on-covid-19/

5. Prem K, Liu Y, Russell TW, Kucharski AJ, Eggo RM, Davies N; Centre for the Mathematical Modelling of Infectious Diseases COVID-19 Working Group, Jit M, Klepac P. The effect of control strategies to reduce social mixing on outcomes of the COVID-19 epidemic in Wuhan, China: a modelling study. Lancet Public Health. 2020;5(5):e261-70. Erratum in: Lancet Public Health. 2020;5(5):e260.

6. Nelson R. COVID-19 disrupts vaccine delivery. Lancet Infect Dis. 2020; 20(5):546.

7. Weller C. While we wait for a COVID-19 vaccine, let's not forget the importance of the vaccines we already have. London: Wellcome; 2020 [cited 2021 Feb 3]. Available from: https://wellcome.org/news/while-we-waitcovid-19-vaccine-lets-not-forget-importance-vaccines-we-already-have

8. McAteer J, Yildirim I, Chahroudi A. The VACCINES Act: deciphering vaccine hesitancy in the time of COVID-19. Clin Infect Dis. 2020;71(15):703-5.

9. World Health Organization (WHO). At least 80 million children under one at risk of diseases such as diphtheria, measles and polio as COVID-19 disrupts routine vaccination efforts, warn Gavi, WHO and UNICEF. Geneva: WHO; 2020 [cited 2021 Feb 3]. Available from: https://www.who.int/news/ item/22-05-2020-at-least-80-million-children-under-one-at-risk-of-diseasessuch-as-diphtheria-measles-and-polio-as-covid-19-disrupts-routine-vaccination-efforts-warn-gavi-who-and-unicef

10. Hoffman J, Maclean R. Slowing the coronavirus is speeding the spread of other diseases. New York: The New York Times; 2020 [cited 2021 Feb 3]. Available from: https://www.nytimes.com/2020/06/14/health/coronavirusvaccines-measles.html

11. Roberts L. Global polio eradication falters in the final stretch. Science. 2020;367(6473):14-15.

12. World Health Organization (WHO). Niger reports new polio outbreak. Geneva: WHO; 2020 [cited 2021 Feb 3]. Available from: https://www.afro.who.int/ news/niger-reports-new-polio-outbreak

13. Global Polio Global Eradication Initiative. World Health Organization (WHO) This Week. Polio this week as of 24 January 2020. Geneva: WHO; 2020 [cited 2021 Feb 3]. Available from: http://polioeradication.org/polio-today / polio-now/this-week/

14. Moss WJ. Measles. Lancet. 2017;390(10111):2490-502. Review.

15. Behrens L, Cherry JD, Heininger U; Swiss Measles Immune Amnesia Study Group. The susceptibility to other infectious diseases following measles during a three year observation period in Switzerland. Pediatr Infect Dis J. 2020;39(6):478-82.

16. Saxena S, Skirrow H, Bedford H. Routine vaccination during covid-19 pandemic response. BMJ. 2020;369:m2392. Erratum in: BMJ. 2020;369:m2435.

17. Marchelin T. Immunization should continue amid pandemic: Health Ministry Jakarta: JAKARTAGLOBE; 2020 [cited 2021 Feb 4]. Available from: https:// jakartaglobe.id/news/immunization-should-continue-amid-pandemic-healthministry/

18. Torres A, Blasi F, Dartois N, Akova M. Which individuals are at increased risk of pneumococcal disease and why? Impact of COPD, asthma, smoking, diabetes, and/or chronic heart disease on community-acquired pneumonia and invasive pneumococcal disease. Thorax. 2015;70(10):984-9. Review. 
19. Wu D, Lu J, Ma X, Liu Q, Wang D, Gu Y, et al. Coinfection of influenza virus and severe acute respiratory syndrome coronavirus 2 (SARS-COV-2). Pediatr Infect Dis J. 2020;39(6):e79.

20. Ding 0 , Lu P, Fan Y, Xia Y, Liu M. The clinical characteristics of pneumonia patients coinfected with 2019 novel coronavirus and influenza virus in Wuhan, China. J Med Virol. 2020;92(9):1549-55.

21. Fernandez M. Vaccinations are plummeting amid coronavirus pandemic. Arlington County: AXIOS; 2020 [cited 2021 Feb 4]. Available from: https:// www.axios.com/children-coronavirus-vaccinations-d2e86bd2-034e-4cc982b9-156fb9621f4f.html

22. Bamforth E. Ohio pediatric vaccines drop by $45 \%$ during coronavirus pandemic, hospital official reports. Cleveland: Cleveland.com; 2020 [cited 2021 Feb 4]. Available from: https://www.cleveland.com/news/2020/06/ ohio-pediatric-vaccines-drop-by-45-during-coronavirus-pandemic-hospitalofficial-reports.html

23. Benin AL, Wisler-Scher DJ, Colson E, Shapiro ED, Holmboe ES. Qualitative analysis of mothers' decision-making about vaccines for infants: the importance of trust. Pediatrics. 2006;117(5):1532-41.

24. Hotez PJ, Nuzhath T, Colwell B. Combating vaccine hesitancy and other $21 \mathrm{st}$ century social determinants in the global fight against measles. Curr Opin Virol. 2020;41:1-7. Review.

25. Yamey G, Schäferhoff M, Hatchett R, Pate M, Zhao F, McDade KK. Ensuring global access to COVID-19 vaccines. Lancet. 2020;395(10234):1405-6.

26. Amanat F, Krammer F. SARS-CoV-2 vaccines: status report. Immunity. 2020; 52(4):583-9. Review.

27. Cohen J. Vaccine designers take first shots at COVID-19. Science. 2020; 368(6486):14-6.

28. Thanh Le T, Andreadakis Z, Kumar A, Gómez Román R, Tollefsen S, Saville M, et al. The COVID-19 vaccine development landscape. Nat Rev Drug Discov. 2020;19(5):305-6
29. The Vaccine Alliance (GAVI). The Gavi COVAX AMC: an investment opportunity. Washington (DC): GAVl; 2020 [cited 2021 Feb 4]. Available from: https://www.gavi.org/sites/default/files/2020-06/Gavi-COVAX-AMC-I0.pdf

30. World Health Organization (WHO). Draft landscape of COVID-19 candidate vaccines. Geneva: WHO; 2021 [cited 2021 Feb 4]. Available from: https:// www.who.int/publications/m/item/draft-landscape-of-covid-19-candidatevaccines

31. Brasil. Ministério da Saúde. Ministério da Saúde abre campanha de vacinação contra a COVID-19 com envio de doses aos Estados. Brasília (DF): Ministério da Saúde; 2021 [citado 2021 Fev 4]. Disponível em: https://www. gov.br/saude/pt-br/assuntos/noticias/ministerio-da-saude-abre-campanhade-vacinacao-contra-a-covid-19-com-envio-de-doses-aos-estados

32. BBC News Brazil. Vacina de Oxford contra COVID é aprovada no Reino Unido; Brasil segue sem data certa. São Paulo: BBC News Brazil; 2020 [citado 2021 Fev 4]. Disponível em: https://www.bbc.com/portuguese/ internacional-55484766

33. Gostin LO. Russia's COVID-19 vaccine breaches crucial scientific and ethical international standards. Moscow: The Moscow Times; 2020 [cited 2021 Feb 4]. Available from: https://www.themoscowtimes.com/2020/08/12/russiascovid-19-vaccine-breaches-crucial-scientific-and-ethical-internationalstandards-a71121

34. Lewis D. China's coronavirus vaccine shows military's growing role in medical research. Nature. 2020;585(7826):494-5.

35. World Health Organization (WHO). WHO target product profiles for COVID-19 vaccines. Geneva: WHO; 2020 [cited 2021 Feb 4]. Available from: https:// www.who.int/publications/m/item/who-target-product-profiles-for-covid19-vaccines

36. Hotez PJ, Corry DB, Bottazzi ME. COVID-19 vaccine design: the Janus face of immune enhancement. Nat Rev Immunol. 2020;20(6):347-8.

37. Graham BS. Rapid COVID-19 vaccine development. Science. 2020; 368(6494):945-6.

38. Harrison EA, Wu JW. Vaccine confidence in the time of COVID-19. Eur $J$ Epidemiol. 2020:35(4):325-30. 